Review article

\title{
Toward a new clinical classification of patients with familial hypercholesterolemia: One perspective from Spain
}

\author{
Luis Masana $^{\mathrm{a}, *}$, Daiana Ibarretxe ${ }^{\mathrm{a}}$, Cèlia Rodríguez-Borjabad ${ }^{\mathrm{a}}$, Núria Plana ${ }^{\mathrm{a}}$, Pedro Valdivielso ${ }^{\mathrm{b}}$, \\ Juan Pedro-Botet $^{\mathrm{c}}$, Fernando Civeira ${ }^{\mathrm{d}}$, Jose López-Miranda ${ }^{\mathrm{e}}$, Carlos Guijarro ${ }^{\mathrm{f}}$, Jose Mostaza ${ }^{\mathrm{g}}$, \\ Xavier Pintóh, Expert group from the Spanish Arteriosclerosis Society \\ ${ }^{a}$ Unitat de Medicina Vascular I Metabolisme. Hospital Universitari Sant Joan. Universitat Rovira I Virgili. IISPV. CIBERDEM, Reus, Spain \\ ${ }^{\mathrm{b}}$ Department of Medicine and Dermatology, Lipids and Atherosclerosis Laboratory, CIMES, University of Málaga, Virgen de La Victoria University Hospital, IBIMA, \\ Málaga, Spain \\ ${ }^{\mathrm{c}}$ Unitat de Lípids I Risc Vascular. Hospital Del Mar. Departament de Medicina. Universitat Autònoma de Barcelona, Barcelona, Spain \\ d Unidad de Lípidos, Hospital Universitario Miguel Servet, IIS Aragón, CIBERCV, Universidad de Zaragoza, Zaragoza, Spain \\ ${ }^{\mathrm{e}}$ Lipid and Atherosclerosis Unit, Department of Internal Medicine / IMIBIC/Reina Sofia University Hospital/University of Cordoba, CIBEROBN, Spain \\ ${ }^{\mathrm{f}}$ Internal Medicine Unit, University Hospital Alcorcon Foundation, Rey Juan Carlos University, Madrid, Spain \\ ${ }^{\mathrm{g}}$ Internal Medicine Service, Hospital Carlos III, Madrid, Spain \\ ${ }^{\mathrm{h}}$ Lipids and Vascular Risk Unit, Internal Medicine, Hospital Universitario de Bellvitge, Hospitalet de Llobregat, Barcelona, Spain
}

\section{H I G H L I G H T S}

- There is a mismatch in clinical and genetic familial hypercholesterolemia diagnosis

- Familial hypercholesterolemia is a syndrome including several entities.

- Monogenic and polygenic familial hypercholesterolemia determines high vascular risk.

- Familial hypercholesterolemia diagnosis has implications to access new therapies.

- A new classification including all FH genotypes and phenotypes is warranted.

\section{A R T I C L E I N F O}

\section{Keywords:}

Familial hypercholesterolemia

Diagnosis

Polygenic familial hypercholesterolemia

Familial combined hyperlipidaemia

PCSK9 inhibitors

\begin{abstract}
A B S T R A C T
The introduction of singular therapies, such as proprotein convertase subtilisin/kexin type 9 inhibitors (PCSK9i), to lower high cholesterol levels requires better classification of patients eligible for intensive lipid lowering therapy. According to the European Medicines Administration, PCSK9i are recommended in primary prevention in familial hypercholesterolemia (FH) patients. Therefore, an FH diagnosis is not simply an academic issue, because it has many clinical implications. The bases of a diagnosis of FH are not entirely clear. The availability of genetic testing, including large genome-wide association analyses and whole genome studies, has shown that some patients with a clinical diagnosis of definite FH have no mutations in the genes associated with the disease. This fact does not exclude the very high cardiovascular risk of these patients, and an early and intensive lipid lowering therapy is recommended in all $\mathrm{FH}$ patients. Because an $\mathrm{FH}$ diagnosis is a cornerstone for decisions about therapies, a precise definition of FH is urgently required.

This is an expert consensus document from the Spanish Atherosclerosis Society.

We propose the following classification: familial hypercholesterolemia syndrome integrated by (1) heterozygous familial hypercholesterolemia: patients with clinically definite $\mathrm{FH}$ and a functional mutation in one allele of the LDLR, ApoB:100, and PCSK9 genes; (2) homozygous familial hypercholesterolemia: mutations affect both alleles; (3) polygenic familial hypercholesterolemia: patients with clinically definite FH but no mutations associated with FH are found (to be distinguished from non-familial, multifactorial hypercholesterolemia); (4) familial hypercholesterolemia combined with hypertriglyceridemia: a subgroup of familial combined hyperlipidaemia patients fulfilling clinically definite FH with associated hypertriglyceridemia.
\end{abstract}

\footnotetext{
* Corresponding author. Facultat de Medicina Universitat Rovira i Virgili, c/. Sant Llorenç, 21, 43007, Reus, Spain.

E-mail address: luis.masana@urv.cat (L. Masana).
} 


\section{Introduction}

The bases for the diagnosis of familial hypercholesterolemia (FH) are not entirely clear. Until a few years ago, only clinical criteria were used, and this continues to be the only diagnostic method in many places. By definition, $\mathrm{FH}$ is a genetic condition; however, in many patients fulfilling the clinical criteria for definite $\mathrm{FH}$, a causative genetic alteration cannot be found; on the other hand, patients with genetic mutations in the FH associated genes lack the expected phenotype [1]. This mismatch can range from $10 \%$ to $50 \%$ of all $\mathrm{FH}$ patients. Data from whole genome analyses suggest that any undiscovered gene could explain the disease in these patients. A more plausible explanation is that these families have a polygenic form of FH [2]. Furthermore, the clinical phenotype is highly variable among FH patients, even in those sharing the same pathogenic mutation, which suggests that FH is a complex syndrome rather than a single disease. The association between FH and cardiovascular risk was established before the genetic era and has been built on the basis of clinical diagnosis. Therefore, according to the latest clinical guidelines, in all FH patients, early and intensive lipid lowering therapy (LLT) should be considered [3,4]. This concept is essential considering the eruption of proprotein convertase subtilisin/kexin type 9 inhibitors (PCSK9i) in the treatment plans. According to the European Medicines Administration, PCSK9i should be prescribed for patients with a previous major cardiovascular event and for FH patients, even as primary prevention, if they continue to have uncontrolled LDL levels after optimal LLT. Due to treatment costs, guidelines for defining the patients eligible for PCSK9i are strict and an FH diagnosis is a cornerstone for deciding on therapy [5,6].

Therefore, the FH diagnosis is not simply an academic issue but has many clinical implications. Because a precise definition of $\mathrm{FH}$ is urgently required, we propose the following classification system.

\section{Familial hypercholesterolemia syndrome}

The term "syndrome" (from the Greek "running together") is applied to a group of signs and symptoms occurring together to characterize a particular condition or phenotype. This condition can have different aetiologies, or its origin can be poorly understood. Considering that $\mathrm{FH}$ is a clinical presentation characterized by very high LDL cholesterol levels with explicit familial aggregation and transmission, high cardiovascular risk and different causes, the use of the term FH syndrome is warranted. The FH syndrome includes genetically and clinically defined $\mathrm{FH}$ according the following entities (Table 1):

\subsection{Heterozygous familial hypercholesterolemia (HFH)}

HFH is the monogenic disease characterized by high LDL concentrations from birth, autosomal co-dominant heritage, presence of corneal arcus or tendon xanthomas in some patients, family history of premature cardiovascular disease and a single functional mutation in one allele of any of the following genes: $L D L R, A P O B$, or PCSK $9^{4,6}$.

Occasionally, rare variants in genes such as $A P O E$, signal transducing adaptor protein family 1 (STAP1) and patatin-like phospholipasedomain-containing family (PNPLA5) can also cause a heterozygous $\mathrm{FH}$ phenotype [7].

The diagnostic requirement is the presence of a functional mutation in one of the abovementioned genes.

\subsection{Homozygous familial hypercholesterolemia ( $\mathrm{HoFH})$}

HoFH is the severe form of the previous disease [8]. Cardiovascular complications, including aortic valve and coronary heart disease, appear before the age of twenty years. This condition can be classified as:

- Real homozygous: when the same mutation affects both alleles of

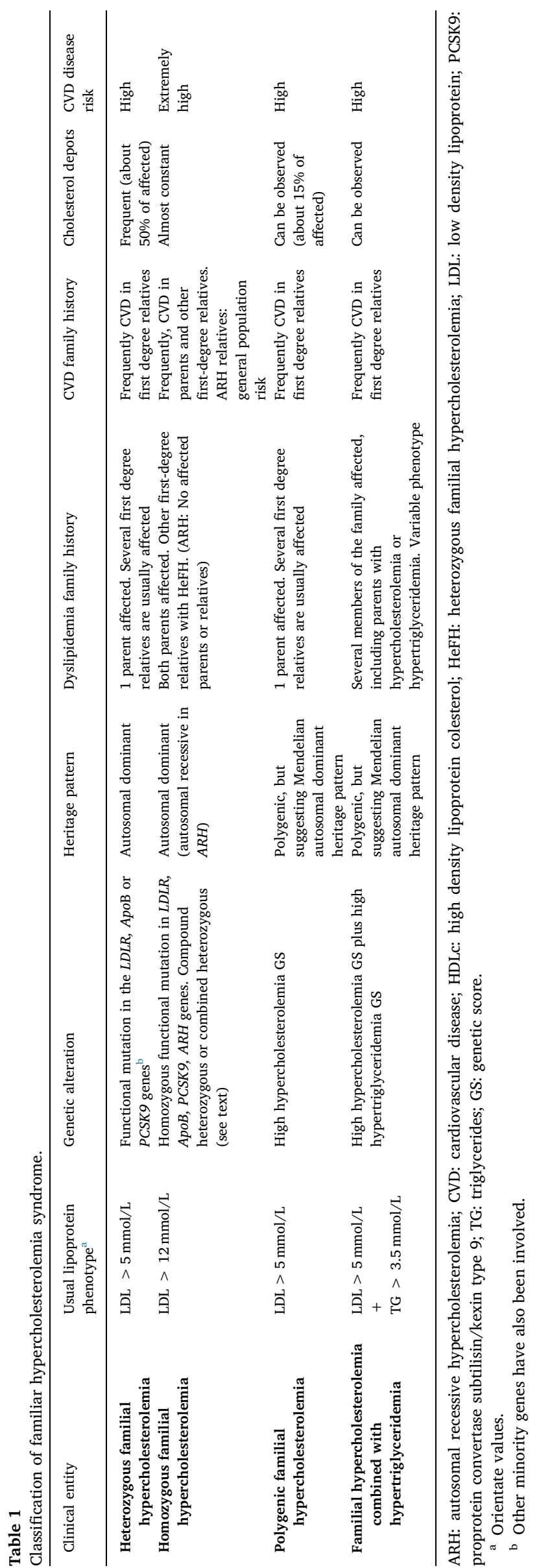


one of the major FH-related genes (LDLR, ApoB, or PCSK9).

- Compound heterozygous: when different mutations affect two alleles of one of the major FH-associated genes.

- Combined heterozygous: when different mutations affect two different FH-related genes.

- Autosomal recessive hypercholesterolemia (ARH). This condition presents with the same HoFH phenotype; however, it is transmitted as an autosomal-recessive disease. Therefore, the parents of the affected child have normal LDL concentrations. These patients have both LDLR adaptor protein 1 (LDLRAP1) gene alleles affected. The severity of the illness falls between the other HoFH forms, and a better response to statins has been observed [9].

\subsection{Polygenic familial hypercholesterolemia (PFH)}

$\mathrm{PFH}$ includes patients with a definite FH diagnosis (according to Simon Broom (SB), Dutch Lipid Clinics Network (DLCN), World Health Organization (WHO) indexes or others), but monogenic alterations associated with FH are not found. PFH accounts for $10-50 \%$ of all clinically definite FH patients depending on the clinical setting $[1,10]$.

These families usually have several members with very high cholesterol levels (LDL above $5 \mathrm{mmol} / \mathrm{L}$ ) suggesting vertical transmission, some with tendon xanthomas or corneal arcus, and a high burden of cardiovascular disease, thereby fulfilling the FH clinical criteria.

An extensive search for alternative candidate genes to explain this lipid disorder, including whole exome sequencing, yielded no new mutations [11].

Several lines of evidence show that these patients have a polygenic form of hypercholesterolemia since they carry a high number of gene variants associated with high LDL levels [2,12] and/or major genetic determinants of high cholesterol levels such as apo E4.

These patients have a high cardiovascular risk because they have a genetically driven high LDL-C concentration, sometimes observed from a young age. Although the risk is probably lower than that of genetically proven heterozygous $\mathrm{FH}$, according to recent data [13], these patients must be managed clinically and treated as $\mathrm{FH}$ according to international guidelines [1,3].

The diagnostic requirement is a definite $\mathrm{FH}$ classification according any of the abovementioned clinical indexes (the yield of either DLCN or SB indexes is similar [10]), despite negative genetic testing. If available, an LDL cholesterol genetic risk score can help to support the diagnosis [12], although it is not formally recommended.

The term PFH must be differentiated from Polygenic Hypercholesterolemia. The latter has been broadly used to define patients with high cholesterol, usually with lower concentrations than those of FH patients, and generally without family aggregation. Polygenic Hypercholesterolemia is by far the most frequent cause of hypercholesterolemia; however, its pathophysiology is not fully understood. Both increased apoB-LDL production and reduced fractional catabolic rates have been observed [14]. Polygenic Hypercholesterolemia is considered to be the product of a polygenic and environment interaction. Therefore, we suggest using the term "Multifactorial Hypercholesterolemia" instead of "polygenic" to avoid confusion.

\subsection{Familial hypercholesterolemia combined with hypertriglyceridemia (FHcTG)}

Familial combined hyperlipidaemia (FCH) was described by Goldstein et al. as a highly prevalent inherited metabolic disorder characterized by both high cholesterol and triglycerides with a variable phenotype [15]. The presence of tendon xanthomas or corneal arcus has also been reported. These patients have a very high cardiovascular risk, and the genetic transmission again suggests an autosomal-dominant pattern. However, after decades of an intense search for the causal gene or genes, none has been detected to date, and $\mathrm{FCH}$ is currently considered a polygenic disease.
These families carry a collection of genes causing high cholesterol and another set determining high triglycerides $[16,17]$. Since the hypercholesterolemic component in some families cannot be distinguished from that of the abovementioned polygenic $\mathrm{FH}$, these families should also be considered as having the FH syndrome. According to the Spanish Arteriosclerosis Society registry, approximately $10-20 \%$ of clinically definite FH patients have high triglycerides. In fact, approximately 1 in 5 patients classified as FCH have LDLR mutations [18]. We propose the term FHcTG to designate a subgroup of FCH patients fulfilling FH criteria; therefore, including patients with very high cholesterol levels (LDL above $5 \mathrm{mmol} / \mathrm{L}$ ) despite concomitant high triglyceride levels.

The diagnostic requirement for this category is to fulfil the diagnostic criteria for definite clinical FH according to the SB, DLCN, and WHO indexes or others, despite high triglycerides and negative genetic testing.

\section{Conclusions}

The intense and differential management of $\mathrm{FH}$, including the introduction of singular therapies such as PCSK9i to lower high cholesterol levels, demands a better definition of this concept. This definition should not exclude patients with severe hypercholesterolemia and familial aggregation because we are not able, at this time, to diagnose the cause of their metabolic defect. On the other hand, the availability of genetic testing, including large genome-wide association analyses and whole genome studies, has shown that about one in three patients with a clinical diagnosis of definite $\mathrm{FH}$ have no mutations in the genes associated with the disease. This fact does not exclude the very high cardiovascular risk of these FH patients with negative genetic tests. Data from extensive genetic studies suggest that there are no hidden genes accounting for this condition. These affected families probably carry a collection of gene variants giving rise to high cholesterol levels. A different aetiology is no reason to exclude these patients from effective therapies aimed at genetically caused hypercholesterolemia.

On the other hand, classical FCH is currently considered a polygenic disease, with the concurrence of a set of gene variants associated with hypercholesterolemia and another associated with hypertriglyceridemia. There is no reason to exclude $\mathrm{FCH}$ patients when hypercholesterolemia is severe and constant from highly efficient therapies simply because they, or their family members, also have high triglycerides.

The term Familial Hypercholesterolemia Syndrome includes all these different conditions characterized by high cholesterol levels, family aggregation, a genetic cause, and increased cardiovascular risk.

We are not challenging the FH definition, screening pathways nor clinical management recommendations. Our aim is to help clinicians to properly classify FH patients by providing a clear-cut definition of various clinical conditions.

The novelty of this classification will probably open up the debate and the exchanges of opinion that we would like to result in a better definition of the relevant individual categories within the framework of familial hypercholesterolemia.

We consider that an official statement on the definition of FH will have an important impact on both physicians and health authorities when designing ASCVD prevention strategies.

\section{Conflicts of interest}

Dr. Civeira reports personal fees from Amgen, Sanofi, FERRER, Merck, during the conduct of the study. Dr. Guijarro reports personal fees from MSD, Amgen, Sanofi, FERRER (advisory panels and lectures). Dr. Lopez-Miranda reports personal fees from Amgen, Sanofi, FERRER, Laboratorios Dr. Esteve, Boehringer Ingelheim-Lilly, outside the submitted work (advisory panel and lectures). Dr. Masana reports personal fees from Amgen, Sanofi, MSD, outside the submitted work. Dr. 
Mostaza reports personal fees from Sanofi, Amgen, outside the submitted work. Dr. Pinto reports personal fees from Amgen, Sanofi, FERRER, RUBIO, ESTEVE, MYLAN, outside the submitted work. The other authors have nothing to disclose.

\section{Author contributions}

LM has written the manuscript. All authors have read, reviewed and equally contributed to the design and content of the paper.

\section{Acknowledgements}

We acknowledge the Sociedad Española de Arteriosclerosis for its scientific support.

\section{References}

[1] B.G. Nordestgaard, M.J. Chapman, S.E. Humphries, H.N. Ginsberg, L. Masana, O.S. Descamps, O. Wiklund, R.A. Hegele, F.J. Raal, J.C. Defesche, A. Wiegman, R.D. Santos, G.F. Watts, K.G. Parhofer, G.K. Hovingh, P.T. Kovanen, C. Boileau, M. Averna, J. Borén, E. Bruckert, A.L. Catapano, J.A. Kuivenhoven, P. Pajukanta, K. Ray, A.F. Stalenhoef, E. Stroes, M.R. Taskinen, A. Tybjærg-Hansen, European Atherosclerosis Society Consensus Panel, Familial hypercholesterolaemia is underdiagnosed and undertreated in the general population: guidance for clinicians to prevent coronary heart disease: consensus statement of the European Atherosclerosis Society, Eur. Heart J. 34 (2013) 3478-3490.

[2] P.J. Talmud, S. Shah, R. Whittall, M. Futema, P. Howard, J.A. Cooper, S.C. Harrison, K. Li, F. Drenos, F. Karpe, H.A. Neil, O.S. Descamps, C. Langenberg, N. Lench, M. Kivimaki, J. Whittaker, A.D. Hingorani, M. Kumari, S.E. Humphries, Use of lowdensity lipoprotein cholesterol gene score to distinguish patients with polygenic and monogenic familial hypercholesterolaemia: a case-control study, Lancet 381 (2013) 1293-1301.

[3] A.L. Catapano, I. Graham, G. De Backer, O. Wiklund, M.J. Chapman, H. Drexel, A.W. Hoes, C.S. Jennings, U. Landmesser, T.R. Pedersen, Ž. Reiner, G. Riccardi, M.R. Taskinen, L. Tokgozoglu, W.M. Verschuren, C. Vlachopoulos, D.A. Wood, J.L. Zamorano, ESC/EAS guidelines for the management of dyslipidaemias: the task force for the management of dyslipidaemias of the european society of cardiology (ESC) and european Atherosclerosis society (EAS) developed with the special contribution of the european association for cardiovascular prevention \& rehabilitation (EACPR), Atherosclerosis 253 (2016) 281-344 2016.

[4] M.F. Piepoli, A.W. Hoes, S. Agewall, C. Albus, C. Brotons, A.L. Catapano, M.T. Cooney, U. Corrà, B. Cosyns, C. Deaton, I. Graham, M.S. Hall, F.D. Hobbs, M.L. Løchen, H. Löllgen, P. Marques-Vidal, J. Perk, E. Prescott, J. Redon, D.J. Richter, N. Sattar, Y. Smulders, M. Tiberi, H. Bart van der Worp, I. van Dis, W.M. Verschuren, European guidelines on cardiovascular disease prevention in clinical practice: the sixth joint task force of the european society of cardiology and other societies on cardiovascular disease prevention in clinical practice (constituted by representatives of 10 societies and by invited experts) developed with the special contribution of the european association for cardiovascular prevention \& rehabilitation (EACPR), Atherosclerosis 252 (2016) 207-274 2016.

[5] U. Landmesser, M.J. Chapman, J.K. Stock, P. Amarenco, J.J.F. Belch, J. Borén, M. Farnier, B.A. Ference, S. Gielen, I. Graham, D.E. Grobbee, G.K. Hovingh, T.F. Lüscher, M.F. Piepoli, K.K. Ray, E.S. Stroes, O. Wiklund, S. Windecker, J.L. Zamorano, F. Pinto, L. Tokgözoglu, J.J. Bax, A.L. Catapano, Update of ESC/EAS Task Force on practical clinical guidance for proprotein convertase subtilisin/kexin type 9 inhibition in patients with atherosclerotic cardiovascular disease or in familial hypercholesterolaemia, Eur. Heart J. (2017), https://doi.org/10.1093/ eurheartj/ehx549 2017 Oct 16

[6] L. Masana, N. Plana, S. Pérez-Calahorra, D. Ibarretxe, I. Lamiquiz-Moneo, J. PedroBotet, M. Suárez-Tembra, P. Valdivielso, E. Ortega, F. Civeira, Dyslipidemia Registry of the Spanish Arteriosclerosis Society. How many familial hypercholesterolemia patients are eligible for PCSK9 inhibition? Atherosclerosis 262 (2017)
$107-112$.

[7] M. Sharifi, M. Futema, D. Nair, S.E. Humphries, Genetic architecture of familial hypercholesterolaemia, Curr. Cardiol. Rep. 19 (2017) 44.

[8] M. Cuchel, E. Bruckert, H.N. Ginsberg, F.J. Raal, R.D. Santos, R.A. Hegele, J.A. Kuivenhoven, B.G. Nordestgaard, O.S. Descamps, E. Steinhagen-Thiessen, A. Tybjærg-Hansen, G.F. Watts, M. Averna, C. Boileau, J. Borén, A.L. Catapano, J.C. Defesche, G.K. Hovingh, S.E. Humphries, P.T. Kovanen, L. Masana, P. Pajukanta, K.G. Parhofer, K.K. Ray, A.F. Stalenhoef, E. Stroes, M.R. Taskinen, A. Wiegman, O. Wiklund, M.J. Chapman, European Atherosclerosis society consensus panel on familial hypercholesterolaemia. Homozygous familial hypercholesterolaemia: new insights and guidance for clinicians to improve detection and clinical management. A position paper from the consensus panel on familial hypercholesterolaemia of the european Atherosclerosis society, Eur. Heart J. 35 (2014) 2146-2157.

[9] R.M. Sánchez-Hernández, P. Prieto-Matos, F. Civeira, E.E. Lafuente, M.F. Vargas, J.T. Real, F.G. Goicoechea, F.J. Fuentes, M. Pocovi, M. Boronat, A.M. Wägner, L. Masana, Autosomal recessive hypercholesterolemia in Spain, Atherosclerosis 269 (2017) 1-5.

[10] J.M. Martín-Campos, N. Plana, R. Figueras, D. Ibarretxe, A. Caixàs, E. Esteve, A. Pérez, M. Bueno, M. Mauri, R. Roig, S. Martínez, X. Pintó, L. Masana, J. Julve, F. Blanco-Vaca, Xarxa d'Unitats de Lípids i Arteriosclerosi (XULA), Autosomal dominant hypercholesterolemia in Catalonia: correspondence between clinicalbiochemical and genetic diagnostics in 967 patients studied in a multicenter clinical setting, J. Clin. Lipidol. 12 (2018) 1452-1462.

[11] M. Futema, V. Plagnol, K. Li, R.A. Whittall, H.A. Neil, M. Seed, Simon Broome Consortium, S. Bertolini, S. Calandra, O.S. Descamps, C.A. Graham, R.A. Hegele, F. Karpe, R. Durst, E. Leitersdorf, N. Lench, D.R. Nair, H. Soran, F.M. Van Bockxmeer, UK10K Consortium, S.E. Humphries, Whole exome sequencing of familial hypercholesterolaemia patients negative for LDLR/APOB/PCSK9 mutations, J. Med. Genet. 51 (2014) 537-544.

[12] M. Futema, S. Shah, J.A. Cooper, K. Li, R.A. Whittall, M. Sharifi, O. Goldberg, E. Drogari, V. Mollaki, A. Wiegman, J. Defesche, M.N. D'Agostino, A. D'Angelo, P. Rubba, G. Fortunato, M. Waluś-Miarka, R.A. Hegele, M. Aderayo Bamimore, R. Durst, E. Leitersdorf, M.T. Mulder, J.E. Roeters van Lennep, E.J. Sijbrands, J.C. Whittaker, P.J. Talmud, S.E. Humphries, Refinement of variant selection for the LDL cholesterol genetic risk score in the diagnosis of the polygenic form of clinical familial hypercholesterolemia and replication in samples from 6 countries, Clin. Chem. 61 (2015) 231-238.

[13] A.V. Khera, H.H. Won, G.M. Peloso, K.S. Lawson, T.M. Bartz, X. Deng, E.M. van Leeuwe, P. Natarajan, C.A. Emdin, A.G. Bick, A.C. Morrison, J.A. Brody, N. Gupta, A. Nomura, T. Kessler, S. Duga, J.C. Bis, C.M. van Duijn, L.A. Cupples, B. Psaty, D.J. Rader, J. Danesh, H. Schunkert, R. McPherson, M. Farrall, H. Watkins, E. Lander, J.G. Wilson, A. Correa, E. Boerwinkle, P.A. Merlini, D. Ardissino, D. Saleheen, S. Gabriel, S. Kathiresan, Diagnostic yield and clinical utility of sequencing familial hypercholesterolemia genes in patients with severe hypercholesterolemia, J. Am. Coll. Cardiol. 67 (2016) 2578-2589.

[14] P.R. Turner, R. Konarska, J. Revill, L. Masana, A. La Ville, P. Jackson, C. Cortese, A.V. Swan, B. Lewis, Metabolic study of variation in plasma cholesterol level in normal men, Lancet 2 (1984) 663-665.

[15] J.L. Goldstein, H.G. Schrott, W.R. Hazzard, E.L. Bierman, A.G. Motulsky, Hyperlipidemia in coronary heart disease. II. Genetic analysis of lipid levels in 176 families and delineation of a new inherited disorder, combined hyperlipidemia, J. Clin. Investig. 52 (1973) 1544-1568.

[16] R.A. Hegele, H.N. Ginsberg, M.J. Chapman, B.G. Nordestgaard, J.A. Kuivenhoven, M. Averna, J. Borén, E. Bruckert, A.L. Catapano, O.S. Descamps, G.K. Hovingh, S.E. Humphries, P.T. Kovanen, L. Masana, P. Pajukanta, K.G. Parhofer, F.J. Raal, K.K. Ray, R.D. Santos, A.F. Stalenhoef, E. Stroes, M.R. Taskinen, A. Tybjærg-Hansen, G.F. Watts, O. Wiklund, European Atherosclerosis Society Consensus Panel. The polygenic nature of hypertriglyceridaemia: implications for definition, diagnosis, and management, Lancet Diabetes Endocrinol. 2 (2014) 655-666.

[17] P.J. Talmud, M. Futema, S.E. Humphries, The genetic architecture of the familial hyperlipidaemia syndromes: rare mutations and common variants in multiple genes, Curr. Opin. Lipidol. 25 (2014) 274-281.

[18] F. Civeira, E. Jarauta, A. Cenarro, A.L. García-Otín, D. Tejedor, D. Zambón, M. Mallen, E. Ros, M. Pocoví, Frequency of low-density lipoprotein receptor gene mutations in patients with a clinical diagnosis of familial combined hyperlipidemia in a clinical setting, J. Am. Coll. Cardiol. 52 (2008) 1546-1553. 